\title{
Recovering long-term aerosol optical depth series (1976-2012) from an astronomical potassium-based resonance scattering spectrometer
}

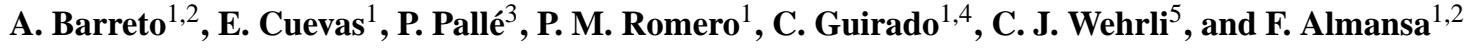 \\ ${ }^{1}$ Izaña Atmospheric Research Center, Meteorological State Agency of Spain (AEMET), Santa Cruz de Tenerife, Spain \\ ${ }^{2}$ Cimel Electronique, Paris, France \\ ${ }^{3}$ Instituto de Astrofísica de Canarias (IAC), Santa Cruz de Tenerife, Spain \\ ${ }^{4}$ Atmospheric Optics Group, Valladolid University (GOA-UVA), Valladolid, Spain \\ ${ }^{5}$ Physikalisch-Meteorologisches Observatorium, Davos, World Radiation Center, Davos, Switzerland
}

Correspondence to: E. Cuevas (ecuevasa@aemet.es)

Received: 25 March 2014 - Published in Atmos. Meas. Tech. Discuss.: 23 April 2014

Revised: 28 October 2014 - Accepted: 29 October 2014 - Published: 3 December 2014

\begin{abstract}
A 37-year long-term series of monochromatic aerosol optical depth (AOD) has been recovered from solar irradiance measurements performed with the solar spectrometer Mark-I, deployed at Izaña mountain since 1976. The instrument operation is based on the method of resonant scattering, which affords wavelength absolute reference and stability (long-term stability and high precision) in comparison to other instruments based purely on interference filters. However, it has been specifically designed as a reference instrument for helioseismology, and its ability to determine AOD from transmitted and scattered monochromatic radiation at $769.9 \mathrm{~nm}$ inside a potassium vapour cell in the presence of a permanent magnetic field is evaluated in this paper. Particularly, the use of an exposed mirror arrangement to collect sunlight as well as the Sun-laboratory velocity dependence of the scattered component introduces some important inconveniences to overcome when we perform the instrument's calibration. We have solved this problem using a quasi-continuous Langley calibration technique and a refinement procedure to correct for calibration errors as well as for the fictitious diurnal cycle on AOD data. Our results showed similar calibration errors retrieved by means of this quasi-continuous Langley technique applied in different aerosol load events (from 0.04 to 0.3), provided aerosol concentration remains constant throughout the calibration interval. It assures the validity of this technique when it is applied in those periods with relatively high aerosol content.
\end{abstract}

The comparative analysis between the recovered AOD data set from the Mark-I and collocated quasi-simultaneous data from the Cimel-AErosol RObotic NETwork (AERONET) and Precision Filter Radiometer (PFR) instruments showed an absolute mean bias $\leq 0.01$ in the 10- and 12-year comparison, respectively. High correlation coefficients between AERONET and Mark-I and PFR/Mark-I pairs confirmed a very good linear relationship between instruments, proving that recovered AOD data series from Mark-I can be used together with PFR and AERONET AOD data to build a longterm AOD data series at the Izaña site (1976-now), suitable for future analysis of aerosols trends and inter-annual variability. Finally, the AOD preliminary trend analysis in the 29-year period from 1984 to 2012 with Mark-I AOD revealed no significant trends.

\section{Introduction}

Long-term measurements are the most important approach for detection of changes in atmospheric composition caused by either variation in natural or anthropogenic emissions, as well as in atmospheric processes and sinks (Collaud Coen et al., 2013).

There is a large number of publications in the literature aimed at analysing long-term trends in variables such as insolation (Wild, 2009), solar irradiance (Dutton and Bodhaine, 
2001), temperature (Jones and Moberg, 2003; Wild, 2009) or aerosol burden (Ruckstuhl et al., 2008; Nyeki et al., 2012; Collaud Coen et al., 2013; Nabat et al., 2013) in order to reveal the spatial and temporal variability of Earth's climate and its atmospheric composition. This information is crucial in the diagnosis of current and past climate as well as in the projections of future climate change, since long-term records enable the development and enhance the skills of atmospheric numerical models through our theoretical understanding of radiative processes.

Such studies have shown the significant radiative impact of volcanic eruptions on at-ground solar irradiance (Dutton and Bodhaine, 2001). The eruption of Mount Pinatubo in June 1991 is an example of a drastic reduction in direct normal irradiance (from 25 to $30 \%$ ), greater than that observed after the El Chichón eruption in 1982, leading to a nearly global but non-uniform tropospheric cooling of $\sim 0.5^{\circ} \mathrm{C}$ (Dutton and Christy, 1992). Anomalies caused by volcanic eruptions used to be the most visible pattern to identify in a long-term record, introducing an important disturbance in trends analysis that must be taken into account. Other studies focused on surface solar radiation (SSR) (Dutton and Bodhaine, 2001; Wild, 2009) have evidenced a decreasing trend in solar radiation at Earth's surface after the mid-1950s, followed by an increasing trend from the mid1980s. These inter-decadal periods with prevailing reduction and enhancement of SSR are also known as solar dimming and brightening, respectively. These variations in SSR are not externally forced by variations of the Sun's radiative output (Lockwood and Fröhlich, 2007), and they are therefore expected to be internal to the Earth's atmosphere. Ruckstuhl et al. (2008) suggested they are a consequence of changing atmospheric transmittance mainly driven by atmospheric aerosol content changes (natural or anthropogenic), cloud changes or a combination of both effects. In this context, there are a number of studies that highlight the existence of a peak in aerosol concentrations in 1988-1990 as a consequence of the increasing anthropogenic aerosol emissions during the solar dimming (Streets et al., 2009; Wild, 2009; Nyeki et al., 2012). This increase in aerosol content was partly responsible for the widespread reduction in sunlight at the Earth's surface observed in some regions, mainly in Central Europe, Africa and some locations in Asia. Subsequently, the air quality regulations introduced since the 1980s in many European countries caused an important reduction in atmospheric aerosol pollution and therefore a consequent brightening over Europe from the late 1980s onward. However, the cause of dimming/brightening is not fully understood and the large-scale significance of this phenomenon is called into question. Thus, the relative importance of aerosol and/or cloud effects on the dimming/brightening is probably different across the globe. There are some studies in the literature aiming to clarify it, such as those performed by Dutton and Bodhaine (2001), Ruckstuhl et al. (2008) and Nyeki et al. (2012). The last two studies used aerosol opti- cal depth (AOD) information at high altitude sites, but they did not find significant trends in this parameter in the periods 1995-2005 and 1995-2010, respectively. Longer aerosol concentration series are required to detect the effect on dimming/brightening processes at high altitude.

Finally, there are other global and regional trends in aerosol concentrations that could affect the overall record. Such trends are often related to the strong decrease in emissions observed in developed countries caused by air quality regulations. However, the evolution of aerosols in the atmosphere results from highly non-linear mechanisms and thence the trend analysis from a long-term record is a complex task (Collaud Coen et al., 2013). Small trends might be detected as a consequence of changes in long-range transport of dust and pollution, changes in local pollution sources, increased emission of pollutants in developing countries or - more difficult to discern - long-term climate variability processes linked to aerosol transport.

At present, poor data quality and changes in the methodology of measurements of existing databases are considered the principal problems to reliably differentiate significant aerosol trends from natural variability in aerosol concentration. Thus, long records of quality controlled aerosol loading data sets are needed to better understand the causes of the observed trends. Due to the lack of availability of reliable multi-year observations, long-term trend analyses of aerosol concentration at present rarely exceed more than 20 years. There exists in the literature some exceptional long and continuous aerosol records, e.g. the oldest AOD series extracted by Ohvril et al. (2009) in Russia, Ukraine and Estonia using measurements of direct solar radiation (Lindfors et al., 2013) or the AOD series measured in Mauna Loa (Shaw, 1979; Holben et al., 2001) by means of sun photometry, and Barrow (Bodhaine and Dutton, 1993), using a four-wavelength nephelometer, both since 1976 . Unfortunately, as is stated by Lindfors et al. (2013), such data exist only for a few selected stations, so existing data sets are difficult to use for most scientific assessments because they are either fragmented or not long enough for these purposes.

Implementation of systematic measurements of aerosol properties at sites with regional or global representation began in the mid-1970s at several remote locations, such as the South Pole, Mauna Loa and Barrow (Collaud Coen et al., 2013). Historically, the most ambitious attempt to monitor background aerosol optical depth levels was organized under the World Meteorological Organization (WMO) Background Atmospheric Pollution Monitoring Network (BAPMoN) program, which operated from 1972 to 1992 and served as a precursor of the current WMO Global Atmospheric Watch (GAW) network (Wehrli, 2008). However, the low precision and stability of the earliest hand-held photometers soon dissuaded the continuity of long-term programs to detect AOD trends with such instruments (WMO, 1994).

Ground-based sites in background conditions, far away from anthropogenic sources, are important for studying 
spatial and temporal variability of atmospheric aerosol properties as well as climate relevant changes and trends. In this context, Izaña is a key site to detect aerosol trends, and interannual variability of dust transport associated with climate variability. Izaña is a remote high-altitude site representative of free troposphere conditions associated with low aerosol concentration values (Rodríguez et al., 2009; Basart et al., 2009; Cuevas et al., 2013). Due to its location in the North Atlantic subtropical region, it is also suitable to study exchange processes between the tropics and mid-latitudes, and for long-term monitoring of frequency and intensity of Saharan dust outbreaks over the North Atlantic.

In this work we have recovered a 37-year data series of monochromatic AOD from long-term solar irradiance measurements performed with the solar spectrophotometer Mark-I, continuously operated since 1976 at Izaña mountain. AOD is the simplest variable to remotely assess the aerosol loading in the atmosphere from ground-based instruments (Holben et al., 2001), because it represents the vertical integral of the aerosol direct irradiance extinction as a measure of atmospheric transmittance (Ruckstuhl et al., 2008). This series encompasses the period between 1976 and 2012. Since as early as 1997, accurate AOD measurements performed with various sun photometers are available at the Izaña Atmospheric Observatory, such as those from the GAW-Precision Filter Radiometer (PFR), since 2001, and from the Cimel-AErosol RObotic NETwork (AERONET) level 2.0, in 1997, and in the 2004-2012 period. Thence, comprehensive comparative analysis can be performed to accurately validate the recovered AOD from the Mark-I data set. Accordingly, in this paper we have studied the ability of the astronomical Mark-I spectrometer to determine AOD data comparable with the AOD measured with sun photometers of accepted aerosol monitoring networks. As a part of the validation, a full comparative analysis has been carried out between the AOD quasi-simultaneously derived from the Mark-I, AERONET and PFR instruments.

\section{The Izaña site: astronomical and atmospheric observations}

Tenerife is one of the oldest atmospheric and astronomical monitoring sites worldwide. The atmospheric monitoring is carried out at the Izaña Atmospheric Observatory (IZO), from the Izaña Atmospheric Research Centre (IARC; http://izana.aemet.es), managed by the State Meteorological Agency of Spain (AEMET; http://www.aemet.es), meanwhile the SolarLab is a telescopic installation for solar observations owned by the Instituto de Astrofísica de Canarias (IAC; http://www.iac.es) at the Teide Observatory (OT). Both centres are located at a distance of $1.5 \mathrm{~km}$ from each other.

IZO, located at an average altitude of $2370 \mathrm{~m}$ a.s.1., provides atmospheric measurements representative of free troposphere conditions due to the quasi-permanent subsidence regime typical of the subtropical region. It entails a frequent winds flow in the lower troposphere resulting in a strong and persistent temperature inversion layer, normally located between 800 and 1500 m a.s.l., below the Izaña Station's level. This shields the station from the pollution from the lower part of the island and separates a dry free troposphere from a relatively fresh and humid oceanic boundary layer (Basart et al., 2009; Cuevas et al., 2013). Thus, Izaña has been a key location in which to perform atmospheric studies with significant measurements over the last 30 years under international programmes (i.e. WMO-GAW, NDACC - Network for the Detection of Atmospheric Composition Change). This remote high-altitude site is indicative of the global aerosol transport because it is located within the broad "dust belt" that extends from the eastern subtropical Atlantic eastwards through the Sahara Desert to the Arabian Peninsula and Southwest Asia (Basart et al., 2009) and it is close to the subtropical barrier, allowing the study of exchange processes between the tropics and mid-latitudes. As Basart et al. (2009) found, aerosol background conditions at IZO are associated with low AOD values, with $\sim 85 \%$ under 0.15 ; meanwhile larger values were associated with dust events more likely to occur during summertime. Thus, a long-range dust transport above the trade wind inversion layer is observed from early summer to early autumn. In these cases, the station is located within the Saharan air layer (SAL), which is a relatively dry and hot well-mixed layer characterized by a relative diurnal stability of aerosol optical properties (Smirnov et al., 1997; Cuevas et al., 2014).

Many ancillary data are collected at IARC for research purposes. Those of interest for this study are accurate AOD measurements from the GAW-PFR, starting in 2001, and from Cimel-AERONET level 2.0 since 2004, with a short campaign during summer 1997.

SolarLab (2395 m a.s.1.) contains a total of six instruments which operate continuously on a daily basis, and in some cases have done so for more than 35 years. The IAC's helioseismology group is one of the pioneer groups in this scientific domain. They participated, jointly with colleagues of the University of Birmingham, in the 1979 key discovery that allowed the fast development of helioseismology: the discovery of the global nature of the $5 \mathrm{~min}$ solar oscillations and therefore their identification as the "Sun's eigenmodes" (García et al., 2007). The first instrument (the so-called "MarkI"), contributed to this find through high precision measurements of the radial velocity of the Sun as a star.

\section{The Mark-I spectrophotometer}

The Mark-I spectrophotometer is a reference instrument in helioseismology. For almost 40 years it has provided highprecision measurements of the radial velocity of the Sun as a star, which has enabled the study of the small velocity fluctuations produced by solar oscillations and the characterization 


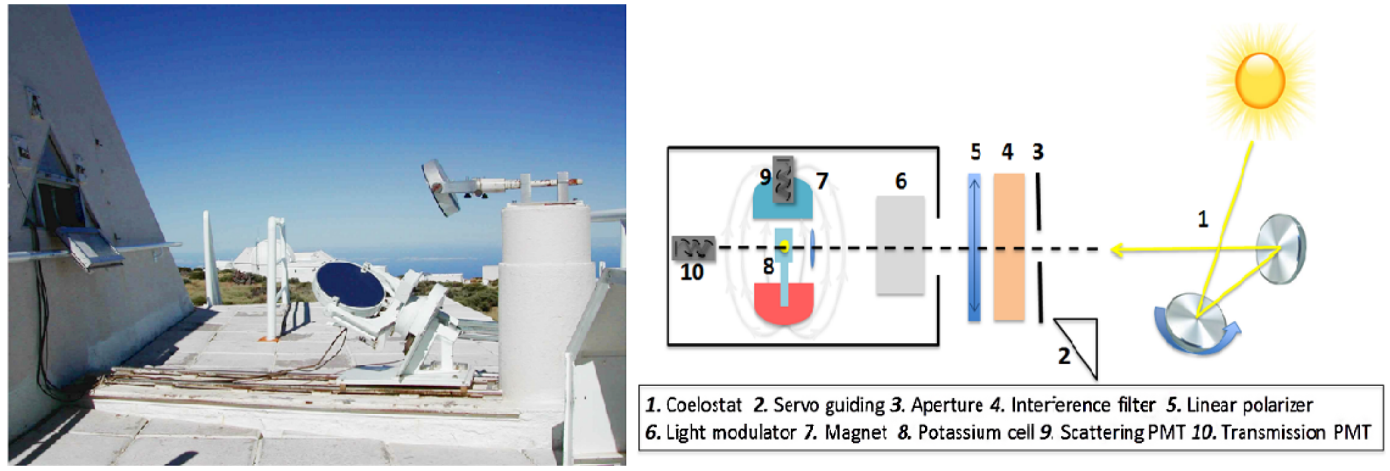

Figure 1. The (a) Mark-I coelostat system at the entrance of the spectrometer; and (b) and diagram of the main constituents of the Mark-I spectrometer. PMT is photomultiplier tube.

of their spectrum (Pallé and Roca-Cortés, 2012; Roca-Cortés and Pallé, 2014). The Mark-I is as a potassium-based resonance scattering spectrometer developed at the University of Birmingham and extensively described in Brooks et al. (1978). It currently serves as one the nodes of the Birmingham Solar Oscillations Network (BiSON) (Pallé and RocaCortés, 2012). The Mark-I employs a magneto-optical filter to study the solar surface and the apparent Doppler velocity of the $769.9 \mathrm{~nm}$ resonance line of the neutral potassium atom in the light integrated over the entire Sun (viewed as a star). This technique offers us an absolute wavelength reference and greater stability in comparison to instruments based purely on interference filters. It has operated since 1976, with its main optical components remaining essentially unchanged. However, these operational conditions present a real handicap due to the continuous changes in some components of the instrument, mainly those installed outdoors for solar tracking. Therefore, as we will see in the next section, it cannot be considered photometrically stable for AOD determination.

The Mark-I is an equatorially mounted spectrophotometer in which sunlight is fed into the instrument using a coelostat (Fig. 1a), an arrangement of open air flat mirrors with changeable orientation during the day to follow the course of the Sun. Following the diagram in Fig. 1b, the output beam is reflected through a hole in the wall into the spectrometer. The collected solar light passes through a $1.5 \mathrm{~nm}$ interference filter, centred at $\sim 770 \mathrm{~nm}$. The light is then directed towards the spectrometer where it traverses a circular polarizer and an electro-optical light modulator (Pallé et al., 1992). The sunlight within this spectral range is affected mainly by atmospheric potassium and $\mathrm{O}_{2}$ absorption. The absorption lines of these atmospheric constituents are displayed in Fig. 2a. It shows that the potassium line centred at $769.89 \mathrm{~nm}$ dominates in this spectral region, although $\mathrm{O}_{2}$ absorption processes are also present. A stable vapour cell of potassium is placed in a longitudinal and permanent magnetic field $(0.18 \mathrm{~T})$, with a resonance line overlapping the solar absorption line (solid black curve in Fig. 2b). The magnetic field causes the two Zeeman components (blue and red curves in Fig. 2b) to sample the circularly polarized KI $7699 \AA$ A solar line. Mark-I measures alternatively each second the intensity of resonantly scattered light due to left-handed $(L)$ and right-handed $(R)$ circularly polarized incident light (Pallé and Roca-Cortés, 2012). Then, the ratio $r=\frac{L-R}{L+R}$ is calculated in blocks of $40 \mathrm{~s}$, filtered by clouds and instrumental errors. Cloud screening process involved in the detection and removal of cloud contaminated data is performed by detection of variations in the photometric signal $(R+L)$ and also in the solar radial velocity curve $\frac{L-R}{L+R}$ of the Sun, which are strongly sensitive to the passage of clouds. As Mark-I observes all of the Sun, the speed of rotation is cancelled (some parts of the Sun are blue-shifted and others red-shifted because the Sun rotates on its axis). When a cloud of any type (low, medium, or even thin cirrus) blocks the Sun, speed is no longer cancelled because a part of the Sun is more visible than another part. As the Sun's speed of rotation is $\sim 2 \mathrm{~m} \mathrm{~s}^{-1}$ for every arc second, when clouds block the Sun, the Doppler velocity sharply increases. This cloud screening method is highly sensitive and reliable, and is carefully done day-byday as a routine job, by the same astronomer to ensure data quality. More details about cloud screening can be found in the Supplement Sect. S1. The ratio gives a measure of the line-shift correction for any intensity fluctuation, and is linearly related to the velocity shift between the Sun and the laboratory. Since the narrow laboratory Zeeman components scans the steepest part of the broader solar line as Earth spins, the scattered light is also sensitive to the Sun-laboratory relative velocity.

As demonstrated in this paper, the most important variables are measured by two photomultiplier tubes (PMTs): the scattering and transmission PMTs on the diagram in Fig. $1 \mathrm{~b}$. The scattering PMT is placed in the transverse direction of the incident beam, recording the information of scattered light $(R+L)$ at any direction as a consequence of the resonant scattering effect inside the vapour cell. The other is set in the direction of the transmitted beam, recording the information of the transmitted light. We have scattered light 

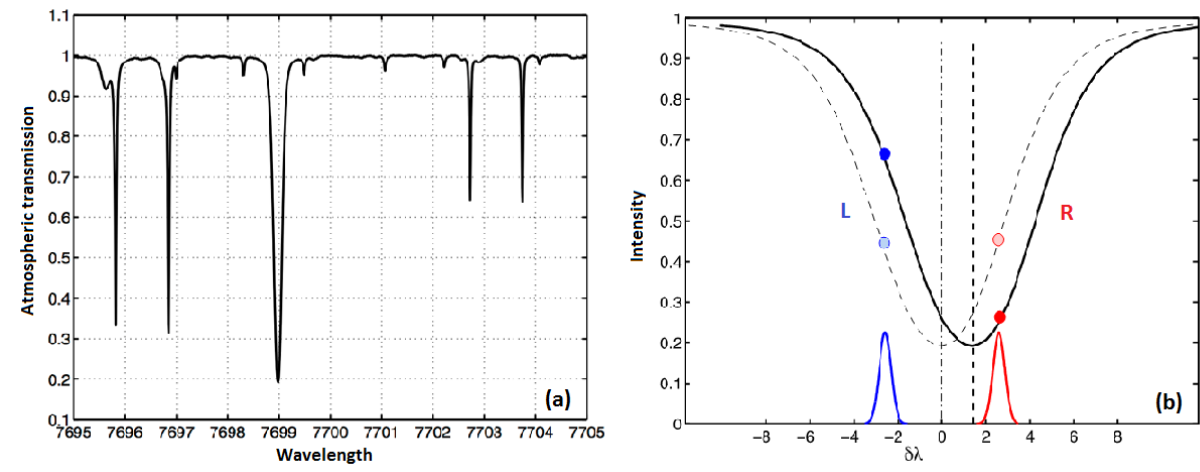

Figure 2. (a) Atmospheric transmission within the Mark-I interference filter bandwidth, and (b) the relative displacement of the solar line (solid black curve) with respect to the laboratory line (dashed curve) measured as a function of $R$ and $L$.

measurements since 1976 but transmitted light information is limited to the period from 1984 to 2002. Since transmitted light is a strictly photometric magnitude and therefore directly related to the atmospheric extinction, we preferably use it to recover AOD information. The information extracted from the scattered component also has a residual velocity contribution that could affect the accuracy of the retrieved AOD. However, due to the lack of transmitted component information for the years 1976, 1977, 1980-1983 and 20032012, AOD was determined from scattered light in these periods. Since this component is the sum of two monochromatic $(R+L)$ measurements in the profile of the solar absorption line, it can also be used for AOD determination. As a result, we have a total of 5786031 solar measurements available to determine AOD information, which correspond to 8084 days of measurements.

\section{Calibration and methodology of AOD determination from Mark-I observations}

Mark-I calibration was performed using the Langley technique (Shaw, 1983; Schmid et al., 1997; Holben et al., 1998). It is the most common approach in photometry to determine the extraterrestrial voltage $V_{0, \lambda}$ from monochromatic photometric measurements performed at different solar elevation angles or air masses. This method is based on the BeerLambert-Bouguer law which implies that the zero-air mass photometer voltage $\left(V_{0, \lambda}\right)$ can be determined by means of a plot analysis of these monochromatic measurements against air masses, provided the atmospheric turbidity remains constant and preferably low over the measurement period. Sunrise air masses ranging from 2 to 5 have been considered for our Langley calculation, which implies between $1 \mathrm{~h} 25 \mathrm{~min}$ and $\sim 2 \mathrm{~h}$ of measurements in equinoxes and solstices, respectively. Corrections for Rayleigh scattering (Kasten and Young, 1989; Bodhaine et al., 1999) and for mixed gases have been included in the calibration procedure.
Due to the important changes in the instrument as a result of degradation of their exposed parts and the replacement of some internal parts, we cannot consider Mark-I as a photometrically stable instrument. Thus, we propose to carry out a quasi-continuous Langley procedure to calibrate the Mark-I. We consider this technique suitable to account for all these changes and to characterize the instrument throughout the whole period of measurements. We have performed such an analysis for the transmitted component by selecting those days with AOD $<0.04$ and correlation coefficients of the fitting plot $\geq 0.99$. The only exception for these thresholds was set during the period from 1992 to 1993, when the Mount Pinatubo eruption (June 1991) released huge amounts of volcanic aerosols into the stratosphere leading to a significant increase in background aerosols levels, with monthly mean AOD values at Izaña up to 0.14 in 1992. For this reason, and to also account for Saharan dust intrusions that may have occurred during this period, the threshold of AOD for the Langley analysis was set at 0.3 , an order of magnitude higher to capture the instrument's variability in this period. If the initial threshold of 0.04 was set for 1992 , no $V_{0}$ values would be retrieved. Due to the high dispersion of extraterrestrial voltages, $V_{0}$, obtained from the scattered component as a consequence of the Sun-laboratory velocity effect on this component, we set the AOD threshold to perform a Langley calculation using this component in 0.3 , in order to have a higher number of daily calibration values to follow the variation in the instrument's calibration. In the following sections we discuss the suitability of those Langley calculations performed under such high aerosol content conditions. Both thresholds have been selected according to an exhaustive data analysis to get a similar number of $V_{0}$ values in every year.

The yearly $V_{0}$ variation (in Digital Numbers, DNs) of the Mark-I solar spectrometer determined from the Langley analysis is shown in Fig. 3. A total of $2462 V_{0} \mathrm{~s}$ were obtained using this technique, the rest of the days were without $V_{0}$ information (about $70 \%$ of them) recovered by means of a cubic spline smoothing process. These values were subsequently reprocessed when a deficient calibration 


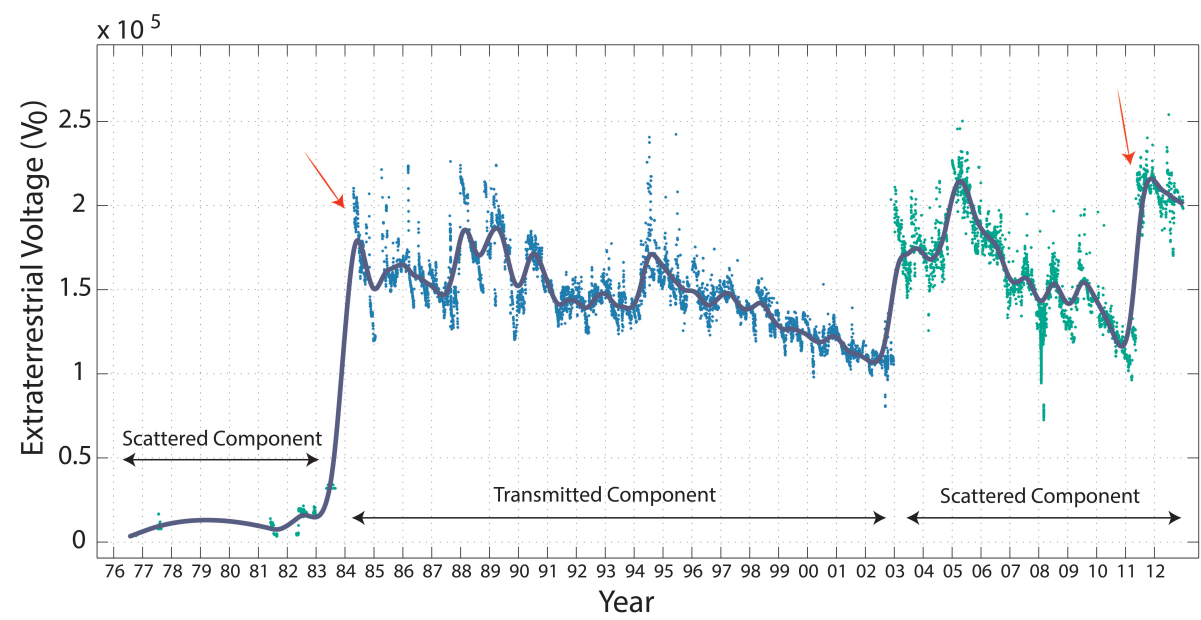

Figure 3. Mark-I extraterrestrial voltage ( $\left.V_{0}\right)$ variation extracted from the scattered (in green) and the transmitted component (in blue) within the period 1976-2012. The smoothing cubic spline is displayed with the violet line. Red arrows mark a change in the PMT of Mark-I.

Table 1. Definitions of the statistics used in this study: $f_{i}$ represents the variable under validation, and Obs $i$ the reference value.

\begin{tabular}{|c|c|c|c|}
\hline \multicolumn{4}{|c|}{ Statistics } \\
\hline Score & Equation & Range & Perfect score \\
\hline Mean bias (MB) & $\mathrm{MB}=\frac{1}{N} \sum\left(f_{i}-\mathrm{Obs}_{i}\right)$ & $-\infty$ to $+\infty$ & 0 \\
\hline Root mean square error (RMSE) & $\mathrm{RMSE}=\sqrt{\frac{1}{N} \cdot\left(f_{i}-\mathrm{Obs}_{i}\right)^{2}}$ & 0 to $\infty$ & 0 \\
\hline Pearson correlation coefficient $(r)$ & $r=\frac{\sum\left(f_{i}-\overline{f_{i}}\right) \cdot\left(\mathrm{Obs}_{i}-\overline{\mathrm{Obs}_{i}}\right)}{\sigma_{f_{i}} \cdot \sigma_{\mathrm{Obs}_{i}}}$ & -1 to 1 & 1 \\
\hline
\end{tabular}

was observed, and were the most important calibration problems associated with the existence of a fictitious diurnal cycle on AOD data. This problem with the calibration procedure was identified by Cachorro et al. $(2004,2008)$ in AERONET AOD data. Following these authors, we considered a refinement procedure in order to improve the $V_{0}$ accuracy. In a first stage, we selected those days affected by a fictitious diurnal cycle on the AOD retrieval, both with convex and concave behaviour, characterized by an amplitude in AOD of $>0.3$. This strong AOD amplitude points to important imprecisions in $V_{0}$ estimation that must be corrected. Again, the threshold was set to correct the major number of events affected by an inaccurate $V_{0}$ estimation. If a set of requirements are fulfilled (i.e. an air mass $m<7$, a minimum of 10 points to perform the fit after outliers removal, and correlation coefficient a $r>0.98)$ a new calibration constant $V_{0}^{\prime}$ can be retrieved as the slope of the AOD vs. $\mathrm{m}^{-1}$ fitting plot. A second reprocessing step was included for AOD amplitude $<0.3$ and $\mathrm{AOD}<0$ events. In this situation, $V_{0}^{\prime \prime}$ was determined considering similar requirements for the $m$ range, the number of points and outliers as for the first stage, but with a lower restriction of the correlation coefficient $(r>0.9)$. The AOD corrections using this recalibration procedure led to AOD changes up to 0.88 . These results, in addition to the final Mark-I AOD series validation, indicate that this methodology is a suitable tool for an effective correction of the instrument's calibration uncertainties.

Figure 3 clearly shows the important variation in the extraterrestrial voltage recovered from this astronomical instrument. It ranges from 3332 to $2.54 \times 10^{5} \mathrm{DNs}$. These significant variations in $V_{0}$ are directly associated with maintenance operations in the coelostat. It is worth mentioning that the transmitted component was used for calibration between 1984 and 2003, and the scattered component in the remaining period. It is therefore expected that changes in $V_{0}$ as a result of this change (see the variation between 1983 and 1984 and between 2003 and 2004). The most important change is observed in 1984, and is attributed to the change in the scattering PMT gains made in this year. In May 2011 the PMT measuring scattered component was replaced, and a consequent variation in $V_{0}$ was observed. Smaller changes $(\sim 50 \%)$ are observed through the whole period, mostly attributed to mirror replacement, cleaning, and realignment processes. This appreciable variability in $V_{0}$ made it challenging to use photometric information from the Mark-I instrument to obtain a long-term series of AOD useful for climatic studies. As we present in Sect. 5, we used efficient techniques published in the literature to overcome this problem. Furthermore, these type of variations are frequently encountered in the typical instruments involved in sun photometry. In fact, 
the AERONET AOD series at Izaña (from 2004 to 2014) was been obtained using a $V_{0}$ series with variations up to $80 \%$. These variations are not related to the individual AERONET sensor's $V_{0}$ stability, but rather associated with differences in the gain settings of the several AERONET master instruments used at the observatory. In spite of these variations, the accuracy of AERONET data is incontestable, showing minimum differences (up to \pm 0.02 ) with PFR series obtained at the same station. We claim that the replacement of main components of the instrument and the continuous changing of the Mark-I external parts have similar consequences for the $V_{0}$ series and they do not prevent retrieval of an AOD series with sufficient accuracy for climate study purposes.

\section{Results}

\subsection{AOD validation}

In order to compare AOD at $769.9 \mathrm{~nm}$ from the Mark-I spectrophotometer with the PFR and Cimel-AERONET sun photometers which take measurements at different wavelengths, we used the Ångström exponent ( $\alpha$ ) following Eq. (1). It relates the AOD value measured at two different wavelengths, $\lambda$ and $\lambda_{0}$. We computed the Angström exponent using PFR data centred at 862,550 and $412 \mathrm{~nm}$, while we used channels centred at $870,675,500$ and $440 \mathrm{~nm}$ in case of CimelAERONET data. In this equation $\lambda$ is $769.9 \mathrm{~nm}$ and $\lambda_{0}$ is 862 and $870 \mathrm{~nm}$ for PFR and AERONET, respectively.

$\operatorname{AOD}(\lambda)=\operatorname{AOD}\left(\lambda_{0}\right) \cdot\left(\frac{\lambda}{\lambda_{o}}\right)^{-\alpha}$

AOD comparison using quasi-simultaneous data extracted from Mark-I, PFR and AERONET was performed to assess the ability of the solar spectrometer Mark-I to retrieve accurate long-term AOD information. We considered coincident measurements performed with these instruments before 2013, including AERONET measurements in June and July 1997, and from 2004 to 2012, as well as PFR measurements in the period 2001-2012, both performed at IZO. Since PFR provides hourly-AOD data, we considered quasisimultaneous data when PFR and Mark-I measurements fell within a \pm 20 min range. It entails a maximum of 65 MarkI observations into the $\pm 20 \mathrm{~min}$ window. A lower temporal range of \pm 10 min was considered to compare the AERONET and Mark-I data. It entails a maximum of 22 Mark-I measurements within this temporal window. Definitions of the main statistics used in this paper are provided in Table 1. The scatter plots of daily AOD values from Mark-I, CimelAERONET and PFR for 1997 and 2001-2012 are displayed in Fig. 4. The main skill scores of the validations are shown in Table 2. A low mean bias (MB) value of -0.008 was obtained for the whole analysis period for the AERONET and Mark-I comparison, with a Pearson correlation coefficient $(r)$ of 0.92 . A total of 95,297 coincident measurements were
Table 2. The skill scores from AERONET/PFR versus Mark-I comparison (transmitted component for 1997, 2001 and 2002, and scattered component from 2003 to 2012). Mean bias (MB), root mean square error (RMSE), Pearson correlation coefficient ( $r$ ), and number of cases $(n)$. The total row indicates the scores obtained using the whole period.

\begin{tabular}{|c|c|c|c|c|c|}
\hline \multirow{2}{*}{ Instrument } & \multirow{2}{*}{ Year } & \multicolumn{4}{|c|}{ Mark-I Spectrometer } \\
\hline & & MB & RMSE & $r$ & $n$ \\
\hline \multirow[t]{11}{*}{ AERONET Cimel } & 1997 & 0.006 & 0.021 & 0.91 & 1973 \\
\hline & 2004 & -0.014 & 0.026 & 0.95 & 3989 \\
\hline & 2005 & -0.013 & 0.023 & 0.96 & 6521 \\
\hline & 2006 & -0.012 & 0.022 & 0.96 & 7587 \\
\hline & 2007 & -0.011 & 0.021 & 0.94 & 12304 \\
\hline & 2008 & -0.008 & 0.025 & 0.94 & 14947 \\
\hline & 2009 & -0.018 & 0.030 & 0.90 & 9521 \\
\hline & 2010 & -0.015 & 0.020 & 0.97 & 8321 \\
\hline & 2011 & -0.009 & 0.020 & 0.96 & 9793 \\
\hline & 2012 & -0.007 & 0.021 & 0.96 & 8598 \\
\hline & TOTAL & -0.008 & 0.034 & 0.92 & 95297 \\
\hline \multirow[t]{13}{*}{ PFR } & 2001 & 0.001 & 0.014 & 0.98 & 376 \\
\hline & 2002 & 0.004 & 0.020 & 0.92 & 1597 \\
\hline & 2003 & -0.008 & 0.019 & 0.74 & 550 \\
\hline & 2004 & 0.001 & 0.032 & 0.86 & 886 \\
\hline & 2005 & 0.007 & 0.029 & 0.94 & 565 \\
\hline & 2006 & -0.003 & 0.018 & 0.97 & 1638 \\
\hline & 2007 & 0.008 & 0.023 & 0.93 & 1942 \\
\hline & 2008 & 0.013 & 0.022 & 0.83 & 282 \\
\hline & 2009 & 0.006 & 0.027 & 0.91 & 1281 \\
\hline & 2010 & 0.002 & 0.015 & 0.97 & 1695 \\
\hline & 2011 & 0.018 & 0.024 & 0.95 & 1975 \\
\hline & 2012 & 0.004 & 0.018 & 0.96 & 1473 \\
\hline & TOTAL & 0.004 & 0.022 & 0.94 & 14260 \\
\hline
\end{tabular}

used in this comparison. The annual comparison shows MB values ranging from -0.018 to 0.006 and high correlation coefficients $(r>0.90)$ and RSMEs below 0.030 .

Regarding the PFR and Mark-I comparison, a total of 14260 matching cases were used, and a MB of 0.004 was obtained. A fairly good agreement was found between both instruments (Table 2), and MB values ranging from 0.018 to -0.008 were obtained. Correlation coefficients were similar to those retrieved in the AERONET and Mark-I comparison, with values $>0.83$, with the exception of 2003, with a markedly lower $r$ value $(r=0.74)$. The most important MB deviations were observed for 2011 with a value of 0.018 . The high MB observed for 2008 was attributed to the sparsity of data. The skill scores in the other years revealed a $\mathrm{MB} \leq 0.01$.

In general, AOD from these instruments correlated quite well each other, with AOD differences between AERONET and Mark-I and between PFR and Mark-I lying within the range 0.01-0.02 (see Table 2). These differences are similar to those obtained between PFR and AERONET (0.01-0.02) reported by Barreto et al. (2013) and Kazadzis et al. (2014) and higher than those retrieved by Nyeki et al. (2012). From 

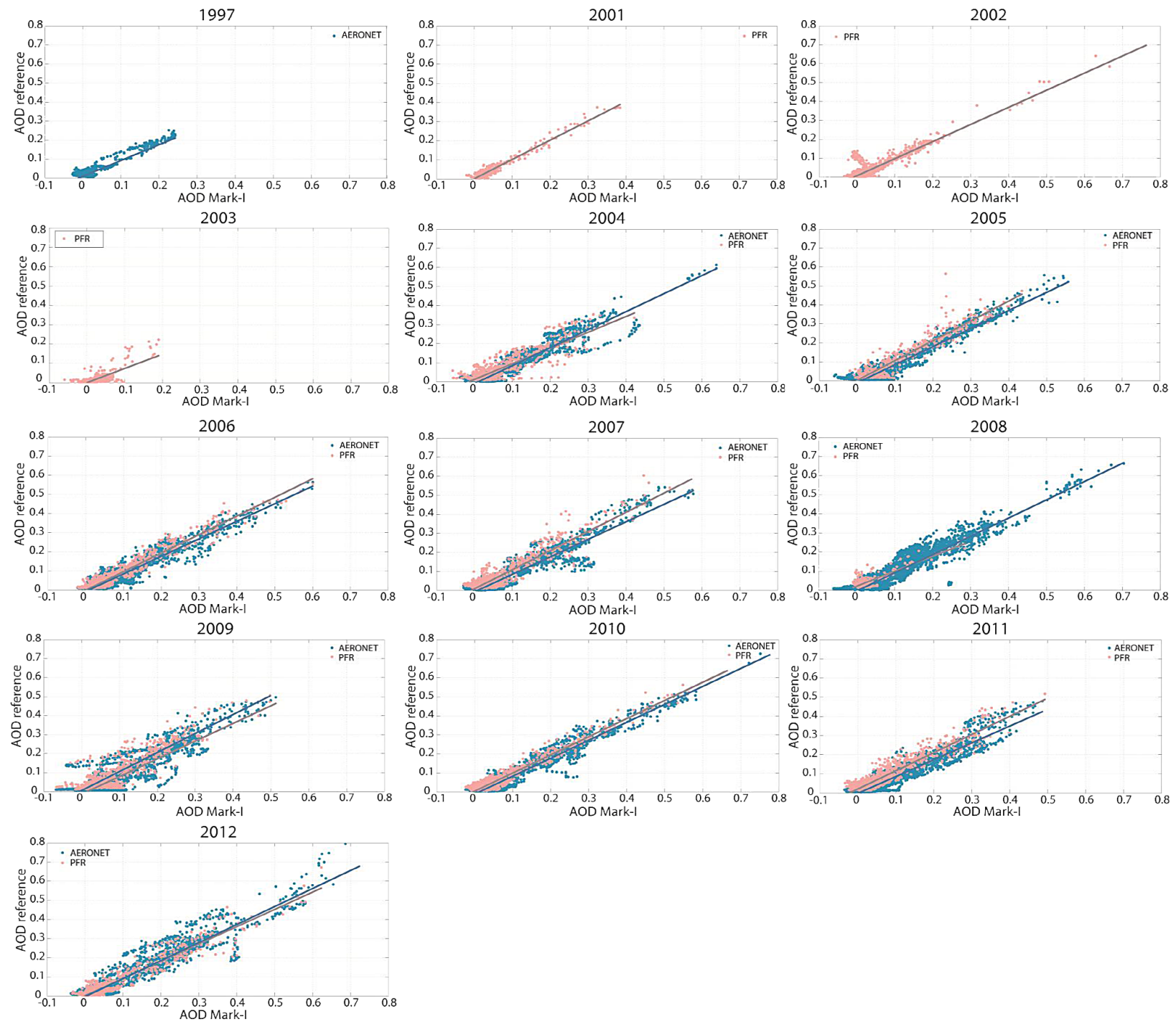

Figure 4. Scatter plots of daily AOD values from the Mark-I against the Cimel-AERONET (blue) and the PFR (pink) for each year (1997 and 2001-2012). Solid lines represent the linear regression lines.

this validation procedure, we can admit that Mark-I has a worse precision than that established for PFR (Wehrli, 2000), and that expected for AERONET masters (0.005-0.009) (see Eck et al., 1999). However, we can be confident of the ability of Mark-I solar spectrometer to obtain AOD with relatively small differences in comparison with reference instruments.

\subsection{Aerosol content impact on instrument's calibration}

In order to assess the suitability of including days with high aerosol loads to perform Langley calibrations we compared quasi-simultaneous and coincident AOD information determined from Mark-I observations (transmitted component) and PFR during 2002. As in the previous section, we considered data quasi-simultaneous when PFR and Mark-I measurements fell within a temporal range of $\pm 20 \mathrm{~min}$. A total of
818 coincident AODs were included, which correspond to 92 different days. The MBs (AODPFR vs. AOD Mark $-\mathrm{I})$ obtained during low aerosol content events $(0.008$ for $\mathrm{AOD} \leq 0.04)$ is of the same order of magnitude to those obtained in case of higher turbidity conditions $(-0.005$ for $0.04<$ AOD $<0.3)$ (Table 3). In principal, the $V_{0}$ values obtained in days affected by rather high aerosol loads could be considered as not suitable, and would result in wrong AOD values. However, our results show that calibrations performed at Izaña under relatively high AOD conditions are affected by similar calibration errors as those carried out in low AOD events, provided aerosol concentration remained constant during the Langley calculation. Despite the fact that aerosol stability conditions are most likely met under low AOD cases, according to our experience at Izaña they are also reached under relatively high aerosols (mineral dust) content conditions. In 
Table 3. Mean bias (MB) and number of cases of the daily coincident comparison between PFR and Mark-I (transmitted component) AOD extracted during 2002.

\begin{tabular}{lll}
\hline AOD range & MB & Number of cases \\
\hline$\leq 0.04$ & 0.008 & 635 \\
{$[0.04,0.1]$} & -0.005 & 75 \\
{$[0.1,0.2]$} & -0.005 & 70 \\
{$[0.2,0.3]$} & -0.005 & 38 \\
\hline
\end{tabular}

Supplement Sect. S2 a detailed analysis of the dependence of aerosol content on the Langley calibration procedure at Izaña station is given. We can see how, as a consequence of the special and specific characteristics of the SAL (vertical mixing and stability) and the position of this station within the SAL, we can follow the classical Langley technique for instrument's calibration under a priori non-ideal conditions $(\mathrm{AOD} \leq 0.3)$. The stability condition here is assured by restricting the calibration analysis to highly correlated Langley calibrations $(r \geq 0.99)$. This is an outstanding result since it tells us that we can obtain reliable $V_{0}$ in long periods of relatively high AOD (up to 0.3 ) affected by mineral dust conditions. Taking into account the long-term behaviour of the stratospheric layer after the eruption of Mount Pinatubo (Ansmann et al., 1996), which had an exponential decay beginning at peak opacity and decaying through subsequent years until background levels were reached, no substantial changes at the daily scale are expected for postPinatubo conditions. Thus, we can assume daily stable and high AOD in this period similar to those exhibited under dust events. In fact, Russell et al. (1993) considered post-Pinatubo conditions suitable to perform accurate Langley calibrations.

\section{AOD series from Mark-I}

Data consistency relies on its homogeneity, and assurance that data variability is not caused by changes in the instrument. The 37-year AOD series determined with the MarkI instrument, as well as the long-term monthly variation of the homogenized data set, are shown in Fig. 5. The latter was calculated using the methodology proposed by Lanzante (1996). It is an iterative procedure that makes it possible to detect outliers and inhomogeneities in the median, evaluate the signal to noise ratio, and finally eliminate those inhomogeneities with a confidence level of $99 \%$. We can see in Fig. 5 the impact of the two most important volcanic eruptions: El Chichón (1982) and Mount Pinatubo (1991).

The monthly mean AOD values at $769.9 \mathrm{~nm}$ from the Mark-I, Cimel-AERONET and GAW-PFR data sets for the common period 2001-2013 are presented in Fig. 6. Similar to the previous section, a good agreement between the three data sets is seen, even though the monthly AOD means were computed with the daily AOD means available for each instrument, so that the days used in the monthly averages do not necessarily coincide. This is crucial in a station as Izaña where AOD values can sharply increase from $<0.03$ to values $>0.5$ (i.e. one order of magnitude) after a Saharan intrusion. Another circumstance to be taken into account in this comparison is that AOD values for AERONET CimelGAW-PFR at $769.9 \mathrm{~nm}$ were estimated using the Ångström exponent $(\alpha)$, which may introduce significant uncertainties, especially for very low AOD. Extremely high AOD values recorded in summer 2012, for both AERONET and CimelGAW-PFR, are well captured by Mark-I. Conversely, the notably low values observed in 2002 by GAW-PFR are also well matched by the Mark-I. This indicates that the recovery of the Mark-I AOD data series back to 1976 is a unique and very valuable data set for studying the long-term inter-annual variability of Saharan dust intrusions over the Atlantic and, in general, for climatological studies of atmospheric aerosols in this region.

Although an accurate analysis of the long-term series is beyond the scope of this work, we conducted a preliminary AOD analysis, as well as a rough assessment of AOD trends from Mark-I data. Since IZO is strongly affected by Saharan dust intrusions during spring and summer, and the fact that these events are driven by atmospheric processes with strong inter-annual variability, we only included winter data in the Mark-I trend analysis. December to February is virtually unaffected by dust conditions. During this period, AOD is below 0.02 and $\alpha$ values are higher than 1.20, indicating that dust intrusions don't affect the station (see http://aeronet.gsfc.nasa.gov/new_web/ V2/climo_new/Izana_500.html?SC\#12). These values are in contrast to the summer period, when the AOD has a peak value of 0.15 in July and $\alpha$ is typically below 0.6 . The trend analysis was performed for the period 1984-2012 following Ruckstuhl et al. (2008), who estimated the trends for different time periods by a fitting plot of monthly mean AOD with a least mean square approximation. This methodology for trend detection is summarized in the Eq. (2), where $Y_{t}$ represents the studied climate variable (AOD in this case) at time $t$, which has the range $(t=1, \ldots, T), \mu$ is a constant term, $\omega$ is the linear AOD trend, $S$ is the seasonal term ,and $N_{t}$ is the monthly mean noise of the time series assumed to be autoregressive on the order of the model. Further details of this methodology can be found in Weatherhead et al. (1998). We have not included in the trend analysis data from 1991 to 1994 because of the Mount Pinatubo eruption (1991). During such volcanic events, the effect of the eruption decays with time (Weatherhead et al., 1998) and therefore introduces non-linear terms not considered in the linear model given in Eq. (2).

$Y_{t}=\mu+\omega \cdot X_{t}+S+N_{t}$.

We estimated the decadal AOD median at Izaña, presented in Table 4. AOD has remained nearly stable at 0.02 since 1984, with values of 0.022 for the 1984-1993 decade, 0.024 


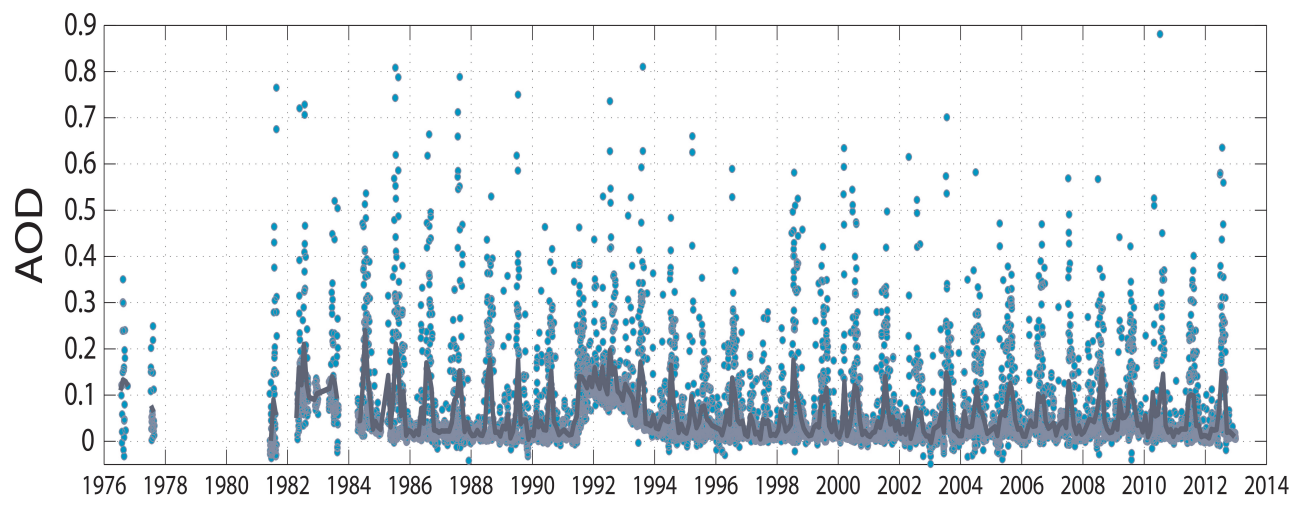

Figure 5. The long-term daily mean AOD (at 769.9 nm) data series at Izaña extracted from the Mark-I scattered data (1976-1983, and 20032012; no data available 1978-1980) and transmitted data (1984-2002). The monthly mean of the homogenized AOD series is displayed with the violet line for the Mark-I.

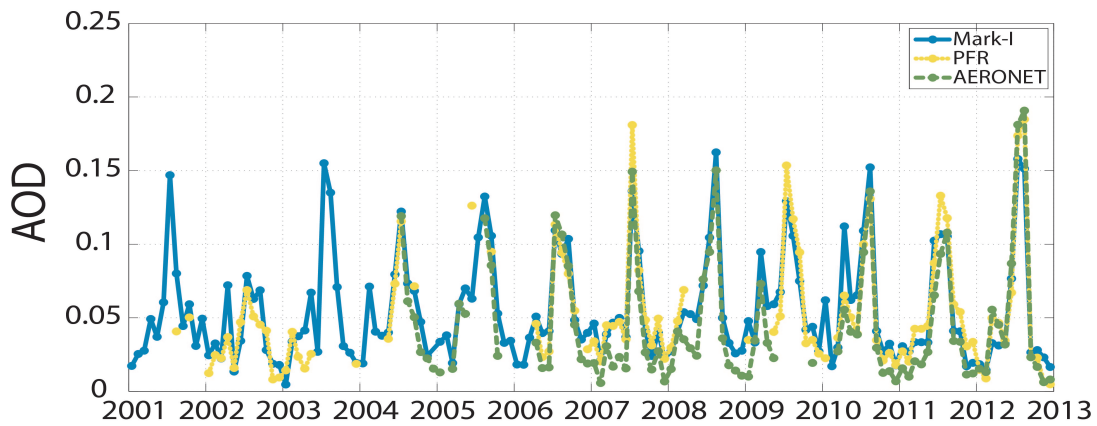

Figure 6. Homogenized AOD monthly means at 769.9 nm for Mark-I 2001-2012 (blue); GAW-PFR 2001-2012 (yellow), and CimelAERONET 2004-2012 (green).

Table 4. Median and standard deviation $(\sigma)$ of the monthly-mean homogenized AOD data set during wintertime (December, January and February).

\begin{tabular}{ccc}
\hline Decade & Median & $\sigma$ \\
\hline $1984-1993$ & 0.022 & 0.012 \\
$1994-2003$ & 0.024 & 0.014 \\
$2004-2012$ & 0.027 & 0.014 \\
\hline
\end{tabular}

in the 1994-2003 decade and 0.027 in the period 2004-2012. Our results do not show the expected decrease in AOD as a result of the solar brightening effect, as stated for example by Streets et al. (2009), who observed a reduction in AOD over Europe at $550 \mathrm{~nm}$ from 0.31 in 1980 to a stable value of 0.26 in 2000-2006. However, we have to keep in mind, first, that IZO is representative of subtropical free troposphere conditions, with their associated very low AOD background values, and hence is less affected by continental pollution, and second, the decisive role played by Saharan dust intrusions in this region in summertime, which shows significant inter-annual and decadal variations modulating the long-term AOD series.
The effect of the Mount Pinatubo eruption is clearly detected in the AOD record of Fig. 5. The El Chichón eruption signal is not as apparent because of the gaps in the data series. From the homogenized monthly series we assessed the AOD anomalies caused by these two important volcanic events. These anomalies are the AOD differences regarding the average AOD of the period 1984-1993. The AOD anomaly observed after El Chichón eruption in 1982 was 0.023. No wintertime data were available to evaluate anomalies in 1983. In the case of Mount Pinatubo, the anomalies observed after the eruption were more important and persistent than for the El Chichón eruption, recording a peak impact in 1992 with an AOD anomaly of 0.049. In turn, the median AOD value during winter 1992 exceeded by $>300 \%$ the median wintertime decadal value in Table 4 . The effects of the Mount Pinatubo eruption on AOD were not significantly reduced until early 1993. The highest monthly AOD value at $769.9 \mathrm{~nm}$ observed at Izaña as a result of the Pinatubo eruption was measured in July 1992 (0.14). These values are consistent with AOD measurements at $500 \mathrm{~nm}$ at Mauna Loa (Hawaii) reported by Russell et al. (1993, 1996). These authors presented peak AOD values at $500 \mathrm{~nm} \sim 0.20$ recorded in August, 1991, when the Pinatubo cloud arrived at the station. 
The time delay in the AOD peak observed at Mauna Loa and IZO is consistent with peak values reported by Stone et al. (1993) at Barrow (in spring, 1992), by Alados-Arboledas et al. (1996) at Almería (in March, 1992) or in Central Europe by Ansmann et al. (1996) (in April 1992). There are different estimations in the literature for the evolution and dissipation of the aerosol cloud from Mount Pinatubo. It is accepted that the $e$-folding decline after maximum volcanic perturbation, with a decay time depending on the location of the station, was about 14 months for Arctic sites like Barrow (Stone et al., 1993), 10 months for MLO (Stone et al., 1993) and between 14 to 15 months for Central Europe (Ansmann et al., 1996). In the IZO case, we estimate a time decay of about 13 months, assuming an exponential decay in AOD $\left(\operatorname{AOD}(t)=\mathrm{AOD}_{\text {peak }} \cdot \exp ^{(-t / T)}\right)$ after reaching its peak value AOD $_{\text {peak }}$, where $T$ represent the time delay.

Regarding the trend analysis over the whole period, our results indicate that there is no significant trend in the AOD at IZO from 1984 to 2012. This result is consistent with the negligible and statistically insignificant AOD trend found by Ruckstuhl et al. (2008) using long-term aerosol concentration measurements at three high-altitude stations located in Switzerland between $995 \mathrm{~m}$ and $3580 \mathrm{~m}$ a.s.1. Nyeki et al. (2012) observed no significant decrease in aerosol concentration in the period 1995-2010 at the same three high-altitude stations after a new recalibration procedure.

These results will be subject of detailed analysis and assessments in future studies, incorporating more information on in situ aerosol measurements at IZO, backward trajectories and other ancillary information accounting for Saharan dust intrusions over the Canary Islands since these modulate the AOD variations at IZO.

\section{Summary and conclusions}

In this work we have assessed the feasibility to determine long-term series of AOD from long-term irradiance measurements using an astronomical spectrometer. This astronomical device, named Mark-I, was specifically designed as a reference instrument in helioseismology. It uses a magnetooptical filter and operates using the method of resonant scattering, based on atomic transitions of potassium induced by incident sunlight. This technique offers us an absolute wavelength reference and greater stability in comparison to instruments based purely on interference filters, but not the required photometric stability to perform instrumental calibration. This due to the use of mirrors (coelostats), continuously exposed outdoors to introduce sunlight into the instrument, whose adjustment and maintenance produce important changes in the instrument calibration that must be corrected. In addition, due to the Sun-laboratory velocity effect on the scattered component, high dispersion in $V_{0}$ introduced additional difficulties in the Mark-I calibration. To solve these problems, we proposed a quasi-continuous Lan- gley calibration procedure which, in principle, is not a standard procedure because it entails calibration under relatively high AOD conditions. However, our results indicated that calibration errors are not dependent on the aerosol load in our station and therefore, $V_{0}$ can be calculated using this technique on those days with relatively high turbidity (AOD up to 0.3 ), provided aerosol concentration remains constant. This result is important in order to extend and assure calibrations for relatively long periods of time when it is not possible to find days with AOD $<0.05$ suitable to perform Langley calibrations, for instance after major volcanic eruptions release aerosols into the atmosphere. Such a global impact was caused by the eruption of Mount Pinatubo, which had an effect lasting from 1991 to 1993. In addition, we considered a refined procedure to improve the calibration that corrects for deficient calibration as well as fictitious diurnal cycles imposed on AOD data.

AOD determined from the Mark-I spectrometer using these procedures was compared with quasi-simultaneous AOD measurements using reference instruments (CimelAERONET and PFR). The 10- and 12-year comparison between AERONET and Mark-I and between PFR and Mark-I, respectively, showed MB values $\leq 0.01$ in both cases, constituting an excellent result. The yearly validation performed in all cases by means of Cimel-AERONET and Mark-I and PFR and Mark-I comparison showed low MB values $\leq 0.02$ and high correlation coefficients (generally $r>0.90$ ). This validation procedure shows the ability of the Mark-I to retrieve an AOD series with small differences in comparison with those of reference instruments (PFR and Cimel). This allowed us to extend the long-term AOD series at the Izaña site with PFR and Cimel (since 2001 and 2003, respectively) back to 1976 using AOD data from the Mark-I. This is a major achievement, and will aid future studies of inter-annual and decadal variations of AOD.

We have performed a preliminary trend analysis for IZO using wintertime Mark-I data. We obtained a nearly stable AOD of 0.022 since 1984, as well as a negligible trend in AOD in the time period from 1984 to 2012. The decadal trend analysis performed using Mark-I data revealed that no significant trend in AOD was observed at IZO. We have also estimated the impact of the major volcanic events occurred since 1976: the eruptions of El Chichón (1982) and Mount Pinatubo (1991). We observed AOD anomalies due to the El Chichón eruption up to 0.023 . More important and persistent anomalies up to 0.049 were associated with the eruption of Mount Pinatubo.

Further analysis, incorporating information from dust events, is required in order to ensure the existence of a statistically significant decrease in AOD since 1980s as confirmation of the solar brightening in our region, as well as other statistically important trends on the AOD signal. This is especially critical in the subtropical region over the North Atlantic since Saharan dust intrusions undergo large interannual and decadal variations modulating AOD variations. 


\section{The Supplement related to this article is available online at doi:10.5194/amt-7-4103-2014-supplement.}

Acknowledgements. This work has been developed within the framework of the activities of the World Meteorological Organization (WMO) Commission for Instruments and Methods of Observations (CIMO) Izaña Testbed for Aerosols and Water Vapor Remote Sensing Instruments. The AERONET sun photometers at Izaña have been calibrated within AERONET-Europe TNA supported by the European Community-Research Infrastructure Action under the FP7 "Capacities" specific programme for Integrating Activities, ACTRIS grant agreement no. 262254. The GAW-PFR network for AOD at WMO-GAW global observatories has been implemented by the World Optical Depth Research and Calibration Center (WORCC). Mark-I operation was supported by the Spanish National Plan of Research and Development under grant no. AYA2012-17803. The authors want to show their appreciation to all IAC researchers and technicians who have operated the Mark-I daily since 1976. Finally, the authors thank the editor and anonymous reviewers for their constructive comments, which helped us to improve the manuscript.

Edited by: O. Torres

\section{References}

Alados-Arboledas, L., Olmo, F. J., Ohvril, H. O., Teral, H., Arak, M., and Teral, K.: Evolution of solar radiative effects of Mount Pinatubo at ground level, Tellus, 49B, 190-198, 1996.

Ansmann, A., Mattis, I., Wandinger, U., Wagner, F., Reichardt, J., and Deshler, T.: Evolution of the Pinatubo Aerosol: Raman Lidar Observations of Particle Optical Depth, Effective Radius, Mass, and Surface Area over Central Europe at 53.4 $4^{\circ}$ N. J. Atmos. Sci., 54, 2630-2641. doi:10.1175/15200469(1997)054<2630:EOTPAR>2.0.CO;2, 1996.

Barreto, A., Cuevas, E., Damiri, B., Guirado, C., Berkoff, T., Berjón, A. J., Hernández, Y., Almansa, F., and Gil, M.: A new method for nocturnal aerosol measurements with a lunar photometer prototype, Atmos. Meas. Tech., 6, 585-598, doi:10.5194/amt-6-585-2013, 2013.

Basart, S., Pérez, C., Cuevas, E., Baldasano, J. M., and Gobbi, G. P.: Aerosol characterization in Northern Africa, Northeastern Atlantic, Mediterranean Basin and Middle East from direct-sun AERONET observations, Atmos. Chem. Phys., 9, 8265-8282, doi:10.5194/acp-9-8265-2009, 2009.

Bodhaine, B. A. and Dutton, E. G.: A long-term decrease in Arctic haze at Barrow, Alaska, Geophys. Res. Lett., 20, 947-950, 1993.

Bodhaine, B. A., Wood, N. B., Dutton, E. G., and Slusser, J. R.: On Rayleigh optical depth calculations, J. Atmos. Ocean. Tech., 16, 1854-1861, 1999.

Brookes, J. R., Isaak, G. R., and van der Raay, H. B.: A resonantscattering solar spectrometer, Mon. Not. R. Soc., 185, 1-17, 1978.

Cachorro, V. E., Romero, P. M., Toledano, C., Cuevas, E., and de Frutos, A. M.: The fictitious diurnal cycle of aerosol opti- cal depth: A new approach for "in situ" calibration and correction of AOD data series, Geophys. Res. Lett., 31, L12106, doi:10.1029/2004GL019651, 2004.

Cachorro, V. E., Toledano, C., Sorribas, M., Berjón, A., de Frutos, A. M., and Laulainen, M. S.: An "in situ" calibrationcorrection procedure (KCICLO) based on AOD diurnal cycle: comparative results between AERONET and reprocessed (KCICLO method) AOD-alpha data series at El Arenosillo (Spain), J. Geophys. Res., 13, 1-11, D02207, doi:10.1029/2007JD009001, 2008.

Collaud Coen, M., Andrews, E., Asmi, A., Baltensperger, U., Bukowiecki, N., Day, D., Fiebig, M., Fjaeraa, A. M., Flentje, H., Hyvärinen, A., Jefferson, A., Jennings, S. G., Kouvarakis, G., Lihavainen, H., Lund Myhre, C., Malm, W. C., Mihapopoulos, N., Molenar, J. V., O’Dowd, C., Ogren, J. A., Schichtel, B. A., Sheridan, P., Virkkula, A., Weingartner, E., Weller, R., and Laj, P.: Aerosol decadal trends - Part 1: In-situ optical measurements at GAW and IMPROVE stations, Atmos. Chem. Phys., 13, 869894, doi:10.5194/acp-13-869-2013, 2013.

Cuevas, E., González, Y., Rodríguez, S., Guerra, J. C., GómezPeláez, A. J., Alonso-Pérez, S., Bustos, J., and Milford, C.: Assessment of atmospheric processes driving ozone variations in the subtropical North Atlantic free troposphere, Atmos. Chem. Phys., 13, 1973-1998, doi:10.5194/acp-13-1973-2013, 2013.

Cuevas, E., Camino, C., Benedetti, A., Basart, S., Terradellas, E., Baldasano, J. M., Morcrette, J. J., Marticorena, B., Goloub, P., Mortier, A., Berjón, A., Hernández, Y., Gil-Ojeda, M., and Schulz, M.: The MACC-II 2007-2008 Reanalysis: Atmospheric Dust Evaluation and Characterization over Northern Africa and Middle East, Atmos. Chem. Phys. Discuss., in press, 2014.

Dutton, E. G. and Bodhaine, B. A.: Solar irradiance anomalies caused by clear-sky transmission variations above Mauna Loa: 1958-99, J. Climate, 14, 3255-3262, 2001.

Dutton, E. G. and Christy, J. R.: Solar radiative forcing at selected locations and evidence for global tropospheric cooling following the eruptions of El Chichón and Pinatubo, Geophys. Res. Lett., 19, 2313-2316, 1992.

Eck, T., Holben, B., Reid, J. S., Dubovik, O., Smirnov, A., O'Neill, N. T., Slutsker, I., and Kinne, S.: Wavelength dependence of the optical depth of biomass burning urban and desert dust aerosols, J. Geophys. Res., 104, 31333-31349, doi:10.1029/1999JD900923, 1999.

García, R. A., Turck-Chieze, S., Jiménez-Reyes, S. J., Ballot, J., Pallé, P. L., Eff-Darwich, A., Mathur, S., and Provost, J.: Tracking Solar Gravity Modes: The Dynamics of the Solar Core, Science, 316, 5831, 1591-1593, doi:10.1126/science.1140598, 2007.

Holben, B. N., Eck, T. F., Slutsker, I., Tanré, D., Buis, J. P., Setzer, A., Vermote, E., Reagan, J. A., Kaufman, Y. J., Nakajima, T., Lavenu, F., Jankowiak, I., and Smirnov, A.: AERONET - a federated instrument network and data archive for aerosol characterization, Rem. Sens. Environ., 66, 1-16, 1998.

Holben, B. N., Tanré, D., Smirnov, A., Eck, T. F., Slutsker, I., Abuhassan, N., Newcomb, W. W., Schafer, J. S., Chatenet, B., Lavenu, F., Kaufman, Y. J., Vande Castle, J., Setzer, A., Markham, B., Clark, D., Frouin, R., Halthore, R., Karneli, A., O'neill, N. T., Pietras, C., Pinker, C., Voss, K., and Zibordi, G.: An emerging ground-based aerosol climatology: Aerosol Optical 
Depth from AERONET, J. Geophys. Res.-Atmos., 106, 1206712097, doi:10.1029/2001JD900014, 2001.

Jones, P. D. and Moberg, A.: Hemispheric and large-scale surface air temperature variations: An extensive revision and an update to 2001, J. Climate, 16, 206-223, 2003.

Kasten, F. and Young, A. T.: Revised optical air mass tables and approximation formula, Appl. Optics, 28, 4735-4738, 1989.

Kazadzis, S., Veselovskii, I., Amiridis, V., Gröbner, J., Suvorina, A., Nyeki, S., Gerasopoulos, E., Kouremeti, N., Taylor, M., Tsekeri, A., and Wehrli, C.: Aerosol microphysical retrievals from precision filter radiometer direct solar radiation measurements and comparison with AERONET, Atmos. Meas. Tech., 7, 20132025, doi:10.5194/amt-7-2013-2014, 2014.

Lanzante, J.: Resistant, robust and non-parametric techniques for the analysis of climate data: theory and examples, including applications to historical radiosonde station data, Int. J. Climatol., 16, 1197-1226, 1996.

Lindfors, A. V., Kouremeti, N., Arola, A., Kazadzis, S., Bais, A. F., and Laaksonen, A.: Effective aerosol optical depth from pyranometer measurements of surface solar radiation (global radiation) a t Thessaloniki, Greece, Atmos. Chem. Phys., 13, 37333741, doi:10.5194/acp-13-3733-2013, 2013.

Lockwood, M., and C. Fröhlich: Recent oppositely directed trends in solar climate forcings and the global mean surface air temperature, P. Roy. Soc. A, 463, 2447-2460, 2007.

Nabat, P., Somot, S., Mallet, M., Chiapello, I., Morcrette, J. J., Solmon, F., Szopa, S., Dulac, F., Collins, W., Ghan, S., Horowitz, L. W., Lamarque, J. F., Lee, Y. H., Naik, V., Nagashima, T., Shindell, D., and Skeie, R.: A 4-D climatology (1979-2009) of the monthly tropospheric aerosol optical depth distribution over the Mediterranean region from a comparative evaluation and blending of remote sensing and model products, Atmos. Meas. Tech., 6, 1287-1314, doi:10.5194/amt-6-12872013, 2013.

Nyeki, S., Halios, C. H., Baum, W., Eleftheriadis, K., Flentje, H., Gröbner, J., Vuilleumier, L., and Wehrli, C.: Ground-based aerosol optical depth trends at three high-altitude sites in Switzerland and southern Germany from 1995 to 2010, J. Geophys. Res., 117, D18202, doi:10.1029/2012JD017493, 2012.

Ohvril, H., Teral, H., Neiman, L., Kannel, M., Uustare, M., Tee, M., Russak, V., Okulov, O., Joeveer, A., Kallis, A., Ohvril, T., Terez, E. I., Terez, G. A., Gushchin, G. K., Abakumova, G. M., Gorbarenko, E. V., Tsvetkov, A. V., and Laulainen, N.: Global dimming and brightening versus atmospheric column transparency, Europe, 1906-2007, J. Geophys. Res.-Atmos., 114, D00D12, doi:10.1029/2008JD010644, 2009.

Pallé, P. L. and Roca-Cortés, T.: Secular measurements of the solar gravitational redshift (1976-2011), Highlights of Spanish Astrophysics VII, Proceedings of the X Scientific Meeting of the Spanish Astronomical Society held on 9-13 July 2012, Valencia, Spain, edited by: Guirado, J. C., Lara, L. M., Quilis, V., and Gorgas, J., 2012.

Pallé, P. L., Regulo, C., Roca-Cortés, T., Sánchez-Duarte, L., and Schmider, F. X.: Solar Radial Velocity and Oscillations as Measured by Sodium and Potassium Resonant Scattering Spectrometers, A\&A, Vol. 254, no. FEB (I), p. 348, 1992.
Roca-Cortés, T., and Pallé, P.: The Mark-I experiment -I. Measurements of the solar gravitational redshift (1976-2013), Monthly Notices of Royal Astronomical Society (MNRAS), 443, 18371848, doi:10.51941093/mnras/stu1238, 2014.

Rodríguez, S., González, Y., Cuevas, E., Ramos, R., Romero, P. M., Abreu-Afonso, J., and Redondas, A.: Atmospheric nanoparticle observations in the low free troposphere during upward orographic flows at Izaña Mountain Observatory, Atmos. Chem. Phys., 9, 6319-6335, doi:10.5194/acp-9-6319-2009, 2009.

Ruckstuhl, C., Philipona, R., Behrens, K., Collaud Coen, M., Dürr, B., Heimo, A., Mätzler, C., Nyeki, S., Ohmura, A., Vuilleumier, L., Weller, M., Wehrli, C., and Zelenka, A.: Aerosol and cloud effects on solar brightening and the recent rapid warming, Geophys. Res. Lett., 35, L12708, doi:10.1029/2008GL034228, 2008.

Russell, P. B., Livingston, J. M., Dutton, E. G., Pueschel, R. F., Reagan, J. A., DeFoor, T. E., Box, M. A., Allen, D., Pilewskie, P., Herman, B. M., Kinne, S. A., and Hofmann, D. J.: Pinatubo and pre-Pinatubo optical depth spectra: Mauna Loa measurements, comparisons, inferred particle size distributions, radiative effects, and relationship to lidar data, J. Geophys. Res., 98, 22969-22985, doi:10.1029/93JD02308, 1993.

Russell, P. B., Livingston, J .M ., Pueschel, R. F., Bauman, J. J., Pollack, J. B., Brooks, S. L., Hamill, P., Thomason, L. W., Stowe, L. L., Deshler, T., Dutton, E. G., and Bergstrom, R. W.: Global to microscale evolution of the Pinatubo volcanic aerosol derived from diverse measurements and analyses, J. Geophys. Res., 101, 18745-18763, 1996.

Schmid, B., Matzler, C., Heimo, A., and Kampfer, N.: Retrieval of optical depth and particle size distribution of tropospheric and stratospheric aerosols by means of sun photometry, IEEE T. Geosci. Remote, 15, 172-182, 1997.

Shaw, G. E.: Aerosols at Mauna Loa: Optical properties, J. Atmos. Sci., 36, 862-869, doi:10.1175/15200469(1979)036<0862:AAMLOP>2.0.CO;2, 1979.

Shaw, G. E.: Sun Photometry, Bull. Amer. Meteor. Soc., 64, 4-10, doi:10.1175/1520-0477(1983)064<0004:SP>2.0.CO;2, 1983.

Smirnov, A., Holben, B. N., Slutsker, I., Welton, E, J., and Formenti, P.: Optical properties of Saharan dust during ACE 2, J. Geophys. Res., 103, 28079-28092, doi:10.1029/98JD01930, 1998.

Stone, R. S., Key, J. R., and Dutton, E. G.: Properties and decay of stratospheric aerosols in the Arctic following the 1991 eruptions of Mount Pinatubo, Geophys. Res. Lett., 20, 2359-2362, 1993.

Streets, D. G., Yan, F., Chin, M., Diehl, T., Mahowald, N., Schultz, M., Wild, M., Wu, Y., and Yu, C.: Discerning human and natural signatures in regional aerosol trends, 1980-2006, J. Geophys. Res., 114, D00D18, doi:10.1029/2008JD011624, 2009.

Weatherhead, E. C., Reinsel, G. C., Tiao, G. C., Meng, X., Cheang, W., Keller, T., DeLuisi, J., Wuebbles, D. J., Kerr, J. B., Miller, A. J., Oltmans, S. J., and Frederick, E.: Factors affecting the detection of trends: statistical consideration and application to environment, J. Geophys. Res., 103, 17149-17161, 1998.

Wehrli, C. J.: Calibrations of filter radiometers for determination of atmospheric optical depth, Metrología, 37, 419-422, doi:10.1088/0026-1394/37/5/16, 2000.

Wehrli, C. J.: Remote sensing of Aerosol Optical Depth in a Global surface network, Diss. ETH No. 17591, doi:10.3929/ethza-005659798, 2008. 
Wild, M.: Global dimming and brightening: a review, J. Geophys. Res., 114, D00D16, doi:10.1029/2008JD011470, 2009.
World Meteorological Organization: Report of the WMO Workshop on the Measurement of Atmospheric Optical Depth and Turbidity, Silver Spring, USA, 6-10 December 1993, Global Atmospheric Watch Technical Note No. 101, WMO TD No. 659, 1994. 